\title{
Histopathological spectrum of intestinal lesions
}

\author{
Meenakshi Masgal', Vishali Vaddadi',*, Anuradha Patil ${ }^{3}$, Anita AM $^{4}$ \\ ${ }^{\mathbf{1}}$ Assistant Professor, ${ }^{\mathbf{2}}$ Junior Resident, ${ }^{\mathbf{3}}$ Professor \& HOD, ${ }^{\mathbf{4}}$ Associate Professor, Dept. of Pathology, Mahadevappa Rampure \\ Medical College, Gulbarga, Karnataka, India
}

*Corresponding Author:

Email: drvishalisatish@gmail.com

\begin{abstract}
Introduction: Intestinal specimens received frequently are of both non neoplastic and neoplastic lesions. Non neoplastic lesions includes non specific enteritis, congenital anomalies, tuberculosis where as carcinoid and carcinomas are neoplastic lesions. Clinical and radiological findings of these lesions are non specific. Therefore histopathological study is required for the diagnosis.

Materials and Methods: One year study was done during the period of June 2016 to May 2017 at M R Medical college, Kalaburagi on 32 intestinal specimens (16 small intestinal and 16 large intestinal).The specimens were processed routinely and special stains were done where ever required.

Results: A wide spectrum of intestinal lesions were studied. Congenital anomalies accounted for $22 \%$ which included meckels diverticulum(4), heterotopic pancreas (1), jejunal atresia (1) and hirschsprung's disease(1). Inflammatory lesions constituted $53.1 \%$ which were mainly chronic non specific inflammation(12), Tuberculosis(4) and diverticulitis(1). Two cases of juvenile polyp, two cases of carcinoid tumor and one case each of ileal lipoma, ileal hemangioma, anal papilloma and signet ring cell adenocarcinoma were reported.

Conclusion: A greater awareness of various diseases affecting the intestines and understanding their pathogenesis, on the part of the pathologist is felt necessary for a better diagnosis. Hence a detailed histopathological study of the intestinal specimens should be done in constant correlation with the clinical and radiological findings for an accurate diagnosis.
\end{abstract}

Keywords: Congenital anomalies ,Tuberculosis, Carcinoid, Hirschprung's, Adenocarcinoma.

\section{Introduction}

The small intestine and large intestine constitutes majority of the gastrointestinal tract and are the sites for broad array of diseases. Both are frequently affected by infectious and inflammatory disorders, but colon is the most common site of gastro intestinal neoplasia in the western populations. ${ }^{1}$

Congenital anomalies of the intestine are more significant cause of morbidity in children than in adults. ${ }^{2}$

Certain conditions like abdominal tuberculosis pose a diagnostic challenge, as non-specific features of the disease may lead to diagnostic delays and development of complications. ${ }^{3}$

Inflammation of the small intestine is relatively common but tumors are rare, accounting for less than 5\% of all gastrointestinal tumors but recently there is rise in incidence ${ }^{4}$. Adenocarcinomas and neuroendocrine tumors of small bowel are the most common subtypes, accounting for approximately $40 \%$ of small bowel tumors. ${ }^{5,6}$.

Colon is affected by wide variety of lesions ranging from inflammatory to neoplastic processes. ${ }^{7}$ Adenocarcinomas are the commonest tumors in colorectal region. ${ }^{8}$

\section{Materials and Methods}

One year prospective study was conducted from June 2016 to May 2017 in Department of Pathology, M
R Medical College, Kalaburagi, Karnataka. A total of 32 resected specimens and biopsies were received in $10 \%$ buffered neutral formalin and were subjected to routine histopathological processing. Sections of 5 micron thickness were taken and stained with H\&E. The final diagnosis was given after detailed study of these sections under the light microscope. Special stains were also done where ever required. The data was analyzed and results were obtained.

\section{Aims and Objectives}

1. To study histopathological spectrum of lesions in the intestine.

2. To study age and sex distribution of these lesions.

\section{Results}

Total 32 cases were studied of which $16(50 \%)$ cases were from small intestine and 16(50\%) cases from large intestine. Age ranged from 4 days to $80 \mathrm{yrs}$. There were 27 Males and 5 females.

In small intestine 12 cases were non-neoplastic, of which 6(37.5\%) cases were congenital anomalies and $4(25 \%)$ cases were abdominal tuberculosis and $2(12.5 \%)$ cases of chronic non specific enteritis. 04 cases were neoplastic which were 01 ileal lipoma, 01 ileal hemangioma and 2 carcinoid tumor [Table 1] 
Table 1

\begin{tabular}{|l|c|c|}
\hline \multicolumn{1}{|c|}{ Lesions } & No. Cases & Percentage \\
\hline 1.Non neoplastic & & \\
\hline -Inflammatory & 02 & $12.5 \%$ \\
(Chronic non specific enteritis) & & \\
-Tuberculosis & $(04)$ & $25 \%$ \\
\hline Congenital anomalies & 06 & $37.5 \%$ \\
-Meckel diverticulum & $(04)$ & \\
-Heterotopic pancreas & $(01)$ & \\
-Jejunal atresia & $(01)$ & \\
\hline 2. Neoplastic & & \\
-Ileal lipoma & 01 & $6.2 \%$ \\
-Ileal hemangioma & 01 & $6.2 \%$ \\
-Carcinoid tumor & 02 & $12.5 \%$ \\
\hline Total & 16 & $100 \%$ \\
\hline
\end{tabular}

In large intestine out of 16 cases 11 were inflammatory lesions, 2 were juvenile polyps, 1 was Hirschsprung disease and 2 were neoplastic (anal papilloma, signet ring cell adenocarcinoma)[Table 2]

\section{Table 2}

\begin{tabular}{|l|c|c|}
\hline \multicolumn{1}{|c|}{ Lesions } & No. Cases & Percentage \\
\hline 1.Non neoplastic & & \\
\hline Inflammatory & 10 & $69 \%$ \\
Diverticulitis & 01 & \\
\hline Juvenile polyp & 02 & $12.5 \%$ \\
\hline Hirschprung disease & 01 & $6.25 \%$ \\
\hline 2.Neoplastic & & \\
\hline Analpapilloma & 01 & $6.25 \%$ \\
\hline Signet ring cell adenocarcinoma & 01 & $6.25 \%$ \\
\hline Total & 16 & $100 \%$ \\
\hline
\end{tabular}

\section{Discussion}

Small intestinal lesions: Present study includes $12(75 \%)$ Non neoplastic cases which is in accordance with the study conducted by Prasad G et al. ${ }^{9}$ Out of these 12 cases, $6(37.5 \%)$ were congenital anomalies, commonest being Meckel's diverticulum constituting 4( $25 \%)$ cases followed by heterotopic pancreas $1(6.2 \%)$ and jejunal atresia $1(6.2 \%)$. Meckel's diverticulum is failure of proximal portion of vitelline duct to obliterate, which is found in $2 \%$ of the population ${ }^{11}$. The lining epithelium in all four cases was of small intestine. Study conducted by Morris et al also showed similar anomalies like Meckels diverticulum and jejunal atresia followed by other congenital anomalies like malrotation, duodenal web and duodenal atresia. ${ }^{10}$

Heterotopic pancreas: A $14 \mathrm{yr}$ male presented with acute pain abdomen and fever which on sonography showed intussusceptions for which Exploratory laparotomy was done and $26 \mathrm{cms}$ of intestinal loop was sent for histopathology. Gross specimen showed gangrenous areas and a polypoidal lesion. Microscopy of polypoidal lesion showed glands and acini divided by thin fibrous septae and intralobular ducts. whereas islet cells were not appreciated. So diagnosis was given as heterotopic pancreas.
Intestinal atresia is one of the most commonest cause of intestinal obstruction in the neonates with an incidence of 1 in 5000.12 Small intestinal atresia accounts for majority of the cases ${ }^{13}$ In the present study 01 case of jejunal atresia was presented with abdominal distention in 4 day old baby boy and was diagnosed radiologically. Later it was confirmed by histopathology.

Another 6/12 non neoplastic cases were inflammatory, of which $4 / 6(25 \%)$ were diagnosed as tuberculosis and $2 / 6(12.5 \%)$ as Chronic non specific enteritis based on the histomorphology. Patients usually present with colicky abdominal pain and vomiting ${ }^{3}$ but in our study patient presented with vague symptoms like loose stools, loss of weight and diffuse pain abdomen. Microscopy showed confluent granulomas, caseating necrosis and langhans giant cells there by confirming the diagnosis of intestinal tuberculosis. The study conducted by Prasad $\mathrm{G}$ et al showed $4.23 \%$ of nonneoplastic lesions as tuberculosis. ${ }^{9}$

Neoplastic lesions of small intestine accounted for $4 / 16(25 \%)$ cases, of which 1 case was ileal lipoma and 2 case were carcinoid tumor and 1 case of ileal hemangioma.

Lipomas are second most common benign tumors of small intestine with mesenchymal origin. ${ }^{14}$ In our 
study 01 case of ileal lipoma patient presented with mass per abdomen, Contrast enhanced Computed tomography scan whole abdomen showed a fat density at the ileo ceacal junction measuring $3 \times 3.5 \mathrm{~cm}$ in size. Histopathology showed bright yellow, encapsulated tumor composed of mature adipocytes with peripherally pushed nucleus.

In our study A 80 year old male patient presented with ileal growth. Grossly the lesion was purple-red and soft and microscopy showed proliferation of numerous small capillaries lined by flat endothelial cells and filled with red blood cells therefore diagnosed as Hemangioma. Hemangioma of small intestine account for $7-10 \%$ of all small intestinal benign neoplasms and can present as infrequent gastro intestinal tract bleeding. ${ }^{15,16} 2$ cases Carcinoid tumors of small intestine were seen in males aged 40yrs and $45 \mathrm{yrs}$ presented with pain abdomen and loose stools. The location of the tumors were appendix and ileum. Grossly lesions were bright yellow in colour and microscopy showed solid sheets of small round cells with small round nucleus having salt and pepper chromatin, mitosis were scant. Our study is in concordance with Prasad et al, showed 6 cases of carcinoid tumors all of which were typical carcinoid. ${ }^{8}$

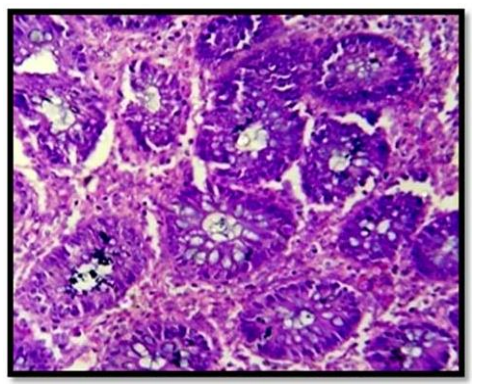

Fig. 1: Duodenal chronic non specific inflammation. H\&E 40x duodenal glands with chronic inflammatory infiltrate

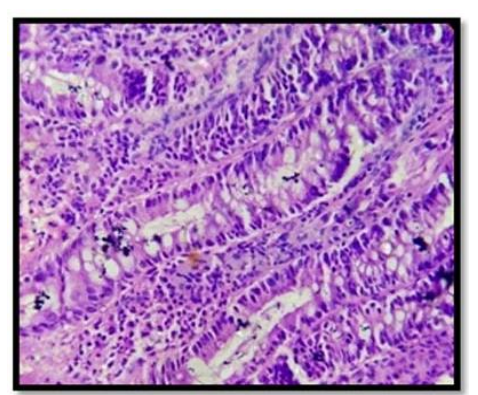

Fig. 2: Chronic non specific inflammation. H\&E 40x lining of intestinal epithelium with lamina propria showing inflammatory infiltrate

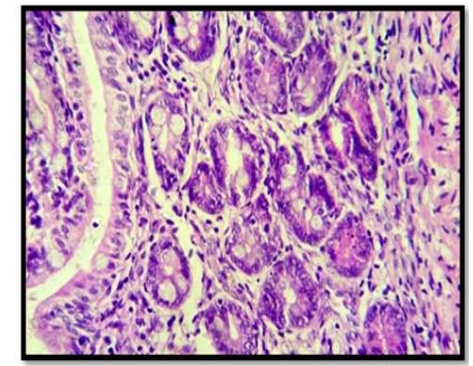

Fig. 3: Diverticulitis. H\&E 40x diverticulum with inflammatory infiltrate

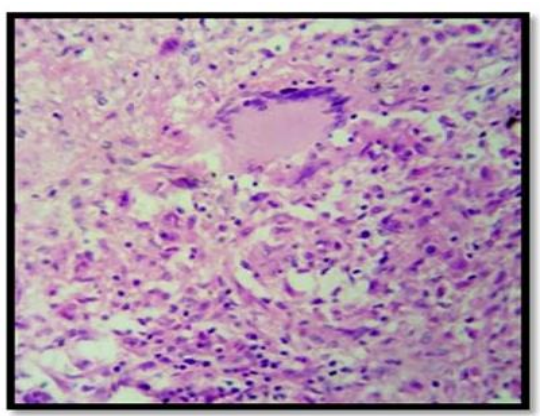

Fig. 4: Tuberculous granuloma. H\&E 40x epithelioid granuloma with langhans gaint cell

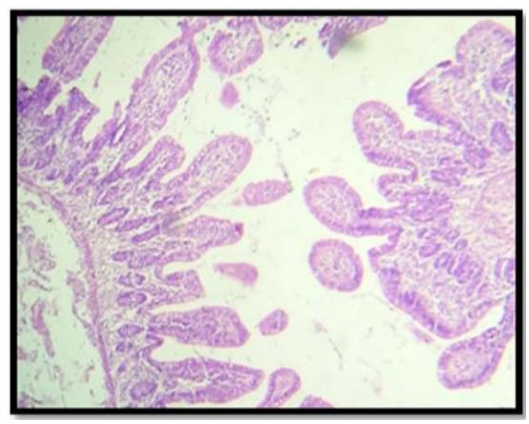

Fig 5: Meckel diverticulum. H\&E 10x all 3 layers of intestine

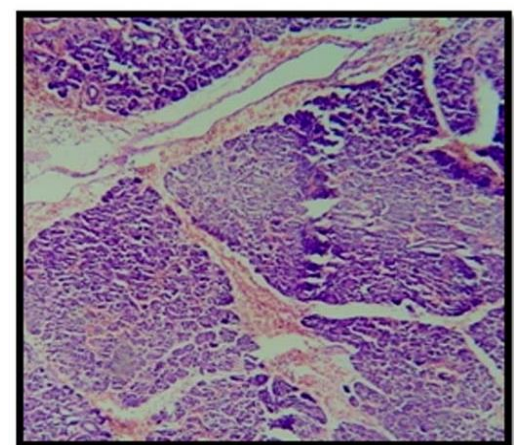

Fig 6: Heterotopic pancreas. $\mathrm{H} \& \mathrm{E} 40 \mathrm{x}$ acinar cells and ducts, no islet cells seen 


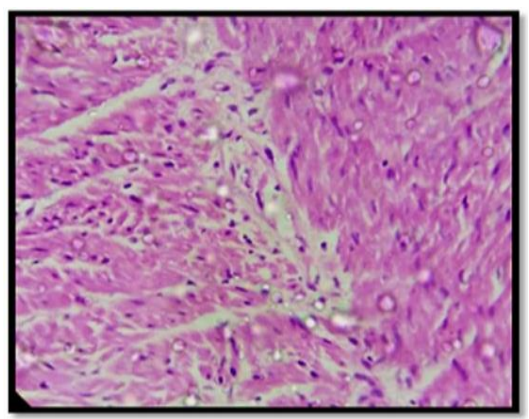

Fig 7: Hirschsprung disease. H\&E 40x absence of ganglion cells

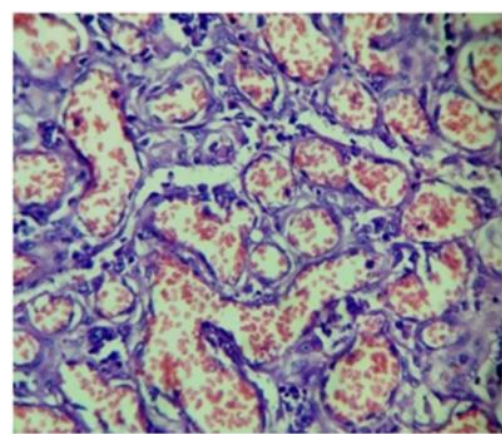

Fig 8: Ileal hemangioma. H\&E 40x small capillaries lined by endothelial cells and filled with red blood cells

Table 3:

\begin{tabular}{|l|l|c|c|}
\hline Sno & \multicolumn{1}{|c|}{$\begin{array}{c}\text { Large intestine } \\
\text { lesions }\end{array}$} & $\begin{array}{c}\text { Riteshsulegaon et } \\
\text { al (2010-2015) } \mathbf{( \% )}\end{array}$ & $\begin{array}{c}\text { Present study June } \\
(\mathbf{2 0 1 6 - M a y 2 0 1 7 ) ( \% )}\end{array}$ \\
\hline 1 & Inflammatory & 76.94 & 69 \\
\hline 2 & $\begin{array}{l}\text { Signet ring cell } \\
\text { adenocarcinoma }\end{array}$ & 4.92 & 6.25 \\
\hline 3 & Anal papilloma & 5.45 & 6.25 \\
\hline 4 & Juvenile polyp & 4.8 & 12.5 \\
\hline 5 & Hirschprungs disease & 7.89 & 6.25 \\
\hline
\end{tabular}

2 cases of juvenile polyps was detected at the age of $5 \mathrm{yr}$ and $3 \mathrm{yr}$ both presented with rectal bleeding. ${ }^{19} \mathrm{On}$ Microscopy cystically dilated glands filled with mucous and edematous stroma infiltrated by mononuclear cells were seen. Dajani YF and Roth SI et al, found rectum as the most common site for juvenile polyps ${ }^{18}$, and 01 case of Hirschsprung's disease was detected in A 4 months old boy presented with abdominal distension. Microscopically there was absence of ganglion cells in the affected segment. Hirschsprung's disease is a congenital disorder presenting with lower intestinal

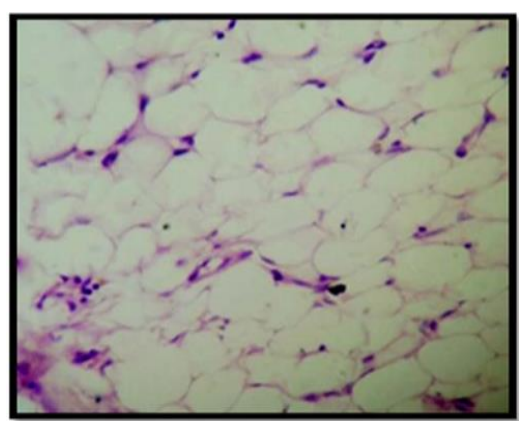

Fig 9: Ileal lipoma. H\&E 40x encapsulated and shows mature adipose tissue

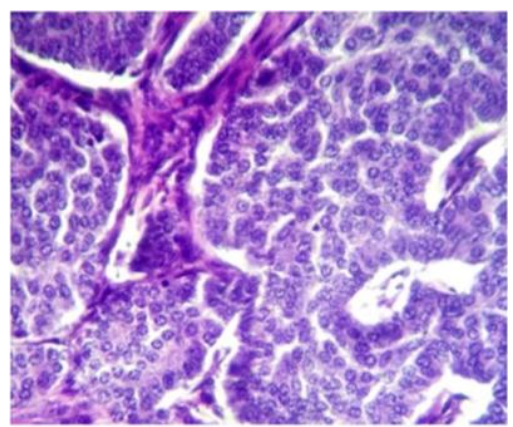

Fig 10: Carcinoid tumor. $H \& E$ 40x small round to oval cells with salt and pepper chromatin

\section{Large intestinal lesions}

16 cases of large intestinal lesions were studied of which 14 were non neoplastic and 2 were neoplastic.The spectrum of non neoplastic lesions included were chronic non specific colitis(10), Diverticulitis(1), Juvenile polyp (2), and Hirschprung's disease.

In the present study most of the lesions were inflammatory in large intestine which is similar to Ritesh Sulegaon et al study. ${ }^{17}$ 
Squamous papilloma of the anal canal is a rare benign epithelial neoplasm that can be mistakenly suspected to be a fibroepithelial anal polyp. ${ }^{20}$ In our study 30 year old female presented with complaints of pain and bleeding per rectum on examination showed a slow-growing mass located in the perianal region. Grossly the tumor is characterized by papillomatous processes and histopathological examination revealed fragments of mature squamous epithelium, without underlying fibrovascular stroma.
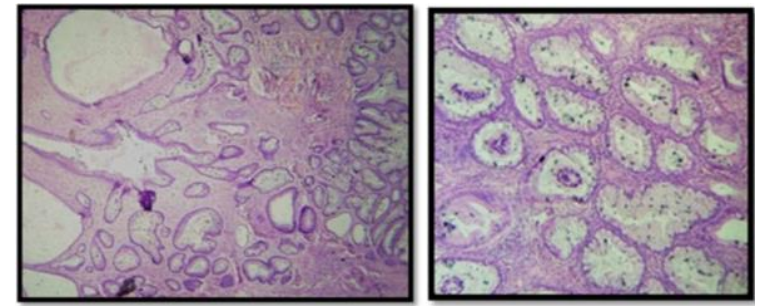

Fig 11(a,b): Juvenile polyp. 10x, 40x H\&E cystically dilated glands lined by cuboidal epithelium filled with mucus and lamina propria showing inflammatory infiltrate

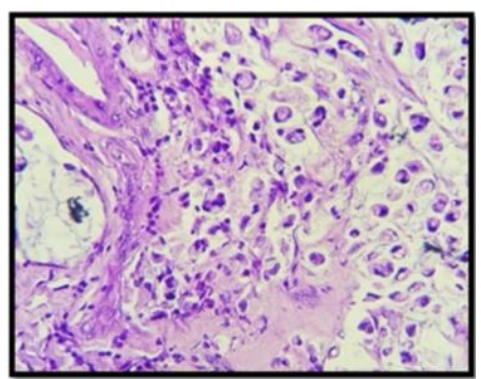

Fig 12: Signet ring cell adenocarcinoma. H\&E 40x sheets of large mucin secreting cells with abundant cytoplasm and peripherally pushed hyperchromatic nucleus

\section{Conclusion}

Disorders of the intestine can be seen in both the extremes of life, from early child hood to elderly. Most of these lesions present vaguely, preventing them from early diagnosis and treatment often leading to grave complications.

Present study emphasises the value of histopathology in diagnosing intestinal lesions as well as understanding pathogenesis and helping the clinicians for appropriate treatment, avoiding complications and improving the survival of the patients.

Funding: No funding sources.

Conflict of interest: None declared.

\section{References}

1. Kumar V, Abbas AK, Aster JC. Robbins and Cotran Pathological Basis of Diseases, $9^{\text {th }}$ Edition,2014;(2):777.
2. Berrocal T, Lamas M, Gutierrez J, Torres I, Prieto C, Luisa del hoyo M. Congenital anomalies of the small intestine, colon and rectum. Scientific exhibit 1999;19:1219-1236.

3. Debi U, Ravishankar V, Prasad kk, Sinha SK, Sharma AK, et al, Abdominal tuberculosis of the gastrointestinal tract Revisited. World J Gastroenterol 2014;20(40):14831-40.

4. A Jemal, R Siegel, E Ward, Y Hao, J Xu, T Murray, et al. Cancer statistics, 2008.CA: A Cancer Journal for Clinicians 2008;58(2):71-96.

5. Pan SY, Morrison H, et al. Epidemiology of cancer of the small intestine. World J Gastrointest Oncol 2011;3(3):3342.

6. M Anzidei, A Napoli, C Zini, et al, Malignant tumours of the small intestine: A review of histopathology, multidetector CT and MRI aspects. Department of Radiological Sciences, 2011;84(1004):677-90.

7. Pavani M, Raghu K, Srikanthbabu Y, et al Histopathological study of lesions of colon A- 5 year study. Int J Scientific Study 2017;5(2):65-8.

8. Bilal sheik, Beigh Ambreen, Farooq summyia et al Spectrum of colorectal lesions on colonoscopic biopsies: a histopathological study in a tertiary care hospital International Journal of Medical Science and Clinical Intervention 2017;4(3):2750-2758.

9. Guru raja PrasadChennakeshavaiah, Dharani vitalapura cheluvegowda. A Histopathological Study Of the Small Intestinal Lesions. Natl J Laboratory Med 2017;6(2):1420.

10. Morris G, Kennedy A Jr, Cohran W. Small bowel congenital anomalies: a review and update. Curr Gastroentrol Rep 2016;18(4):16.

11. Juan Rosai, Rosai and Ackerman's, Surgical Pathology, $9^{\text {th }}$ Edition,Vol-1, Elsevier,675.

12. Burjonrappa S, Crete E, Bouchard S.Comparative out comes in intestinal atresia: a clinical outcome and pathophysiology analysis. Pediatr Surg Int 2011;27(4):437-42.

13. Etensel B, Temir G, Karkiner A, Melek M, Edirne Y, Karaca I, Mir E. Atresia of the colon. J Pediatr Surg 2005;40(8):1258-68.

14. Balamoun H, Doughan S. Ileal lipoma - a rare cause of ileocolic intussusception in adults: case report and literature review. World J Gastrointest Surg 2011;3(1):13-5.

15. PJ Garvin, V Herrmann, DL Kaminski, VL Willman, Benign and malignant tumors of small intestine. Curr Probl Cancer 1979;(3):1-46.

16. P S Ramanujam, KS Venkatesh, L Bettinger, JT Hayashi, MC Rothman, MJ Fietz Hemangioma of the small intestine : case report and literature review. Am J Gastroenterol 1995;(90):2063-64.

17. Sulegaon R, Shete S, Kulkarni D. Histological Spectrum of Large Intestinal Lesions with Clinicopathological Correlation. J Clin Diagnostic Res 2015; 9(11):30-4.

18. Dajani YF, Kamal MF. Colorectal juvenile polyps: An epidemiological and histopathological study of 144 cases in Jordanians. Histopathology 1984;8(5):765-79.

19. Roth SI, Helwig EB. Juvenile polyps of the colon and rectum. Cancer 1963;16:468-79.

20. Gerada $\mathrm{J}$ et al. Squamous papilloma of the anal canal. Endoscopy 2012;44:E1-E2.

How to cite this article: Masgal M., Vaddadi V., Patil A., M Anita. Histopathological spectrum of intestinal lesions. J Diagn Pathol Oncol 2018;3(4):330-34. 